
passed it in a direction upwards and outwards through the right wall of the original cyst, opening another large cyst with a similar flow of pus. I then passed the cautery vertically downwards for about an inch or an inch and a half, but without result; and the same negative result followed when I attempted to pass it though the left wall. I was able, however, to open another cyst in the direction of the right hypochondrium. In all these cases pus escaped. The cautery in each instance passed through at least half an inch to an inch of dense cyst wall, and its entry into the cyst was indicated by a distinct slip followed by a flow of pus. Altogether six cysts, counting the original one, were opened up in this manner; all were situated to the right of the tumour, all were of the character described above, and all had a large capacity.

The progress of the case after this operation has been one of uninterrupted improvement. Suppuration was very profuse for about a fortnight; the temperature, however, rarely exceeded $101^{\circ}$. During this time the lining membrane of the cysts was detached in long shreds of slough, and after this process was completed suppuration ceased, and the whole of this portion of the tumour seemed to collapse to its present dimensions. On the left side, in the situation of the punctures which failed to enter cysts, suppuration continued active, all the tissue between the punctures becoming involved in the process and breaking down to form a large cavity, from which pus continued to be dissharged profusely for many months and in a diminished quantity up to the present time. It has, however, gradially granulated up so that now it is represented by only a small cavity.

It remains to say a few words about the size of the tumour and the present condition. For the last six months the lower margin of the tumour has occupied a situation of two inches above the umbilicus, whereas before the operation it reached two inches below. The greatest circumferential measurement is thirty-one inches, against thirty-five before the operation. The respiratory murmur has returned over the back of the right lung. The heart has not descended from its abnormal position. For many months the patient has enjoyed as good health as he did before the operation, and he has been quite free from pain. The failure to find hooklets and the absence of anything like daughter cysts in this case, throw some little doubt upon the diagnosis of hydatid disease; but its cystic character and its evident relation to the liver make it, I think, impossible to have been anything else. One can only speculate as to the form of hydatid represented in this case. That there has been an exceptional development of cysts is manifest, but the difficulty is to decide whether these cysts have been extruded from the wall of the parent cyst-as in the exogenous variety of hydatid,or whether they have formed within the parent cyst. Ziegler alludes to both varieties under the names of "echinococcus granulosus" and "echinococcus hydatidosus" respectively. The points of special interest in this case are the size and number of the cysts forming the tumour, the thickness and hardness of their walls, and the success which has attended the treatment by the cautery.

Huddersfield.

\section{A CASE OF DIGITAL EXPLORATION THE PYLORUS.}

BY JOHN W. TAYLOR, F.R.C.S.,

SURGEON TO THE BIRMINGHAM AND MIDLAND HOSPITAL FOR WOMEN CONSULTING SURGEON TO THE WOLVERHAMPTON HOSPITAL FO BIRMINGHAM AND MIDLAND SKIY AND XOCK HOSPITAK.

M. P-, aged forty-three, married, no children, came îrom a distance to consult me in July, 1889. She had history of romiting for several months, the vomit being copious, acid, and frothy. For six weeks the vomiting had been constant after every meal. On examination, the stomach appeared to be moderately dilated. On careful palpation it was thought that a small amount of thickening in the neighbourhood of the pylorus could be detected, but this was always doubtful. The patient was considerably ernaciated; her general condition, apart from this, appeared to be satisfactory. On inquiry into her past history, she stated that she had suffered from ulcer of the stomach with hamatemesis fifteen years ago, but that since that time until the date of her present illness her health had been good. The illness fifteen years ago had been severe, and she was treated largely by hypodermic injections of morphia, the marks of which are still visible. A diagnosis was muade of pyloric obstruction with moderate dilatation of the stomach, and it was considered highly probable that the gradual contraction of an old cicatrix following gastric ulcer might be responsible for her present symptoms. For two months the case was under occasional observation. She was treated first of all by a mixture containing carbolic acid and bromides, and afterwards by washing out the stomach, but without any success. The vomiting persisted, and the patient steadily but slowly decreased in weight week by week.

As the case appeared to be a suitable one for Loreta's operation, and no benefit had been obtained by other means, I proposed to open the stomach and examine the pylorus, dilating this if $I$ found it to be contracted. This proposal was accepted by the patient, and on Sept. 18th of the same year I opened the abdomen above the umbilicus. No tumour was found on external examination of the stomach and pylorus, but the former was dilated and extended for some little distance below the umbilicus. The incision was enlarged downwards to the left of the umbilicus, and having drawn out the stomach I opened it midway between the curvatures at the pyloric end, inserted my finger and searched for the internal opening of the pylorus. For a considerable time I could not find it, the stomach from within feeling like a closed sac. When discovered, over a sharply defined ridge of mucous membrane at the highest part of the stomach on the right side, the finger entered it easily and could pass without difficulty down into the duodenum. There seemed to be but little, if any, increase of muscular structure in this situation, and the stomash and intestine were so acutely bent at the pylorus that the orifice was completely obscured until the stomach had been raised and a thorough search was made. With so limited an experience of digital exploration from within the stomach, I would not presume to say how much this differed from the normal ; but on careful consideration of the case the lkinking of the gut-which only thorough distension of the stomach in the recumbent position seemed able to undo-must, I think, have been the cause of the gastric dilatation and the prolonged and persistent vomiting. I closed the wound in the stomach with a continuous Lembert suture, and the incision in the parietes with silkworm gut. The patient recovered from the exploration without any untoward symptoms, nutrient suppositories being used exclusively for severaldays as food. From this date the vomiting ceased, and the patient has had no return of it. This is now more than a year ago. In a few months after operation she had increased two stones in weight, and when I showed the case at the recent meeting of the British Medical Association the improvement had been well maintained. Although I did not sew the stomach to the abdominal wall, adhesions have probably taken place between the site of the stomach incision and the under-surface of the liver or the parietes, it being the rule to find adhesions after intra-abdominal suture. If so, this has held the stomach at a higher level, and the passage of food from the stomach into the small intestine has been rendered less difficult.

The kinking of tubular viscera, such as bowel or ureters, is evidently a much more common cause of obstruction than has hitherto been generally recognised. In a case of enormous dilatation of the stomach with pyloric tumour which was under the care of Dr. Foxwell and myself the real obstruction was found after death not to be directly due to the tumour, but to a fold or kink of the intestine below the pylorus, and secondarily to the tumour, which was the cause of the kink. Within recent years (since 1885) Glénard has described a series of intestinal displacements, or "enteroptoses," as accompanying gastric neurasthenia with moderate dilatation, and his writings on enteroptosis, or Glénard's disease, have been either defended or thoughtfully considered by several other writers by Professor Dujardin-Beaumetz, by Féréol, Trastour, Cuilleret, and Sanctis. According to his view many cases of gastric neurasthenia are due to direct mechanical causes; and although he places his fundamental lesion in prolapse of the right flexure of the colon, it is evident from his illustrations that, if these have any basis of fact, acute pyloric flexure, less in degree, but such as I have been describing, must play no unimportant part in the pro. 